\title{
Off-label indication: acyclovir as an anti-HIV drug?
}
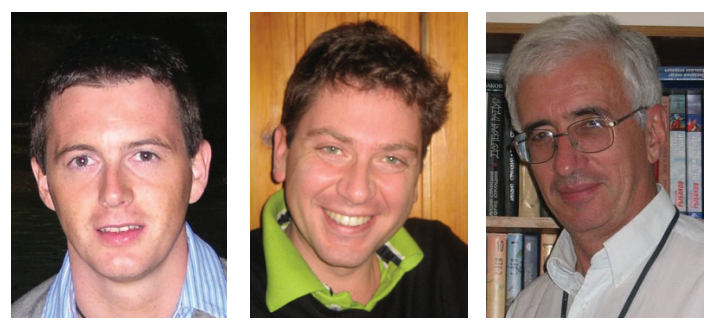

"Accumulating data

demonstrates that

HSV-2 affects both HIV

transmission...and HIV

pathogenesis..."

Christophe Vanpouille, PhD, Andrea Lisco, MD, PhD \& Leonid Margolis, $\mathrm{PhD}^{\dagger}$

†Author for correspondence: Program of Physical Biology, Eunice Kennedy Shriver National Institute of Child Health \& Human Development, 10 Center Drive, Building 10, Room 9D58, Bethesda, MD 20892, USA

" Tel.: +1 3015942476 .' Fax: +1 3014800857 =margolis@helix.nih.gov

Herpesviruses (HHVs) emerged from a common ancestral mammalian virus 200 million years ago and thus accompanied every step of human evolution [1]. Generally, in the course of evolution in human populations, microbes become less pathogenic. Some of the HHVs, such as HHV-6 and -7 , have a high prevalence and are not associated with any adult human diseases. By contrast, infections with other HHVs (HSV-1 and -2, VZV, EBV, CMV and KSHV) have lower prevalences and cause well defined diseases. In the early 1980s, severe clinical expressions of HHV infections were among the first recognized manifestations of AIDS [2], and those clinical conditions, among others (sustained by different microbes), define AIDS [3].

Accumulating data demonstrates that HSV-2 affects both HIV transmission [4,5] and HIV pathogenesis [6,7]. However, other HHVs, even low-pathogenic HHV-6 and -7 , affect HIV pathogenesis as well [8]. During coevolution with their hosts, these viruses have acquired several cellular genes (encoding chemokines and chemokine-like receptors), which affect HIV by modulating chemokine spectra and the expression of HIV receptors and coreceptors [8-10].

Multiple publications provide evidence that several HHVs play a role in HIV disease irrespective of their morbidity [6-12]. By targeting these HHVs, one can hope to indirectly affect HIV disease. Fortunately, unlike in the case of $\mathrm{HIV}$, an efficient, selective and relatively nontoxic drug targeting $\mathrm{HHVs}$ has been developed. This drug is acyclovir (ACV).

\section{Acyclovir}

$\mathrm{ACV}$ is a guanosine analog that was synthesized in the late 1970s. It is the most commonly used antiviral drug, and it was seen as the start of a new era of designed antiviral medicines. $\mathrm{ACV}$ was designed by Gertrude B Elion and colleagues, and for this accomplishment, among others, she was awarded the 1988 Nobel Prize in Physiology or Medicine [13].

66

"...these viruses have acquired several

cellular genes, which affect HIV by

modulating chemokine spectra and

the expression of HIV receptors and coreceptors..."

ACV is particularly active against HSV-1, HSV-2 and VZV [14]. It is also active against other HHVs (EBV, CMV, HHV-6, HHV-7 and KSHV), although with lower potency [15]. ACV's specificity in suppressing HHVs is based on viral metabolism. $\mathrm{ACV}$ is converted into acyclovir monophosphate (ACV-MP), specifically by herpesviral kinases; cellular kinases are far less efficient in phosphorylating ACV into ACV-MP than viral enzymes. Subsequently, ACV-MP is further phosphorylated by cellular kinases into the active triphosphate form, acyclovir triphosphate (ACV-TP), which is a very potent inhibitor of herpesviral DNA polymerase. Its incorporation into viral DNA results in chain termination and viral DNA polymerase inactivation [16]. The affinity of ACV-TP for herpesviral polymerase is approximately 100-times greater than its affinity for cellular DNA polymerase, thus ACV-TP specifically terminates viral rather than cellular DNA elongation. This difference in affinity, in addition to the already high selectivity of ACV's phosphorylation by viral kinases, explains ACV's efficiency and safety. Indeed, the dose of ACV that halts herpesviral replication does not interfere with the synthesis of cellular DNA. Only at high doses does such interference occur and result in cell death. This phenomenon was the basis for the use of $\mathrm{ACV}$ as an anticancer drug in experiments in which neoplastic cells were transfected with HSV thymidine kinases. Also, similar experiments were performed to selectively eliminate HIV-1-infected

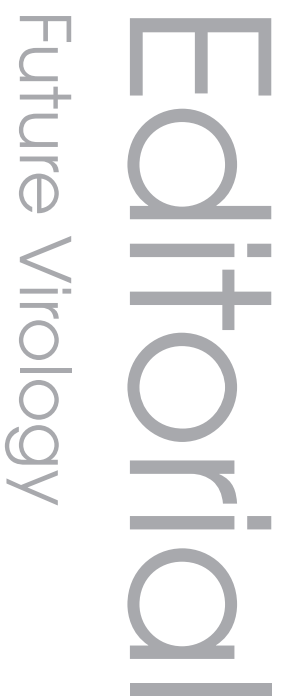

future medicine $^{\text {por }}$ fsg 
cells transfected with HSV-thymidine kinases [17]. However, these experimental strategies using ACV to selectively kill neoplastic or HIV-infected cells were not developed further, leaving ACV exclusively as a selective anti-HHV drug.

\section{ACV inhibits HHVs in HIV-1-infected individuals: disrupting the vicious circle of this troublesome duo}

The molecular mechanism by which ACV suppresses HHVs, described above, explains why ACV does not affect viruses other than HHVs.
Nevertheless, since HSV-2 is a common HIV copathogen, several clinical trials evaluating the effects of HSV-2 suppression in HIV-1-co-infected patients were performed. These trials demonstrated that HSV-2 suppression with ACV or its prodrug valacyclovir reduces plasmatic, genital and rectal HIV-1 load in HSV-2-co-infected individuals [18-22]. These recent trials are in agreement with early reported survival benefits in cohorts of ACV treated HIV-1-infected patients who expressed a high incidence of clinically identifiable $\mathrm{HHVs}$ (HSV-1, HSV-2 and VZV) [23].

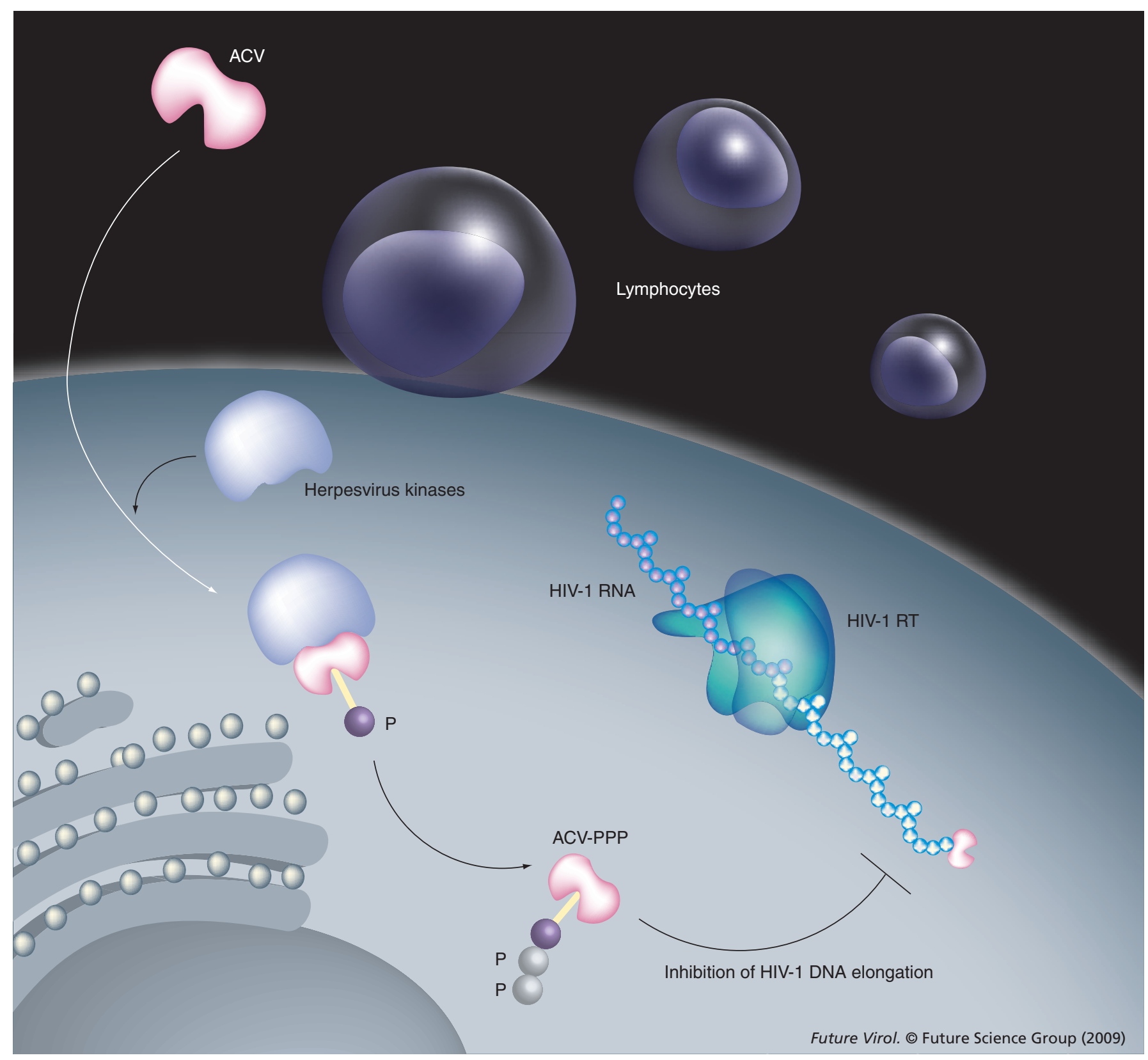

Figure 1. Acyclovir is activated into a HIV-1 reverse transcriptase inhibitor in herpesvirus-infected human tissues. In herpesvirus-infected lymphocytes, ACV is phosphorylated by herpesviral kinases. The resulting monophosphorylated ACV is converted into ACV-PPP by cellular kinases. HIV-1 reverse transcriptase incorporates ACV-PPP into the nascent viral DNA chain, causing its obligate termination. ACV: Acyclovir; ACV-PPP: Acyclovir triphosphate; RT: Reverse transcriptase. 
HIV and HHVs, in particular HSV-2, are a troublesome duo. It seems that they are engaged in a vicious circle in which one worsens the impact of the other. On one hand, people co-infected with HIV and HSV-2 have more frequent HSV-2 mucosal reactivations due to inefficient immune control [7]. On the other hand, HIV-1 genital and plasma load are markedly increased during HSV-2 reactivations [6,7], probably because of the recruitment of immune cells (which provide new targets for HIV) and HIV-1 long-terminal repeat transactivation by HSV proteins [24,25]. Also, this vicious cycle results in an increase in the risk of HIV-1 acquisition and transmission due to the HSV-induced disruption of genital mucosa, the recruitment of activated cells and the increase of HIV-1 genital load [4,5].

However, in two clinical trials, HSV-2 suppressive therapy with ACV failed to protect HSV-2-seropositive women or men who have sex with men from HIV-1 acquisition [26,27]. Whether this failure is due to the subjects' low adherence, to behavioral disinhibition, to low ACV dosage [28-31], or simply to the insufficiency of HSV-2 suppression for prevention of HIV-1 acquisition, remains to be understood. Despite the failure of efforts to prevent HIV-1 acquisition by suppressing HSV-2, there is no doubt that HSV-2-suppressive therapy with ACV in HIV-1-co-infected individuals results in a significant decrease of HIV-1 viral load [18-22]. This decrease has been attributed to the indirect suppression of HSV-2-mediated inflammation. However, the surprising discovery of the direct effect of ACV on HIV-1 reverse transcriptase (RT) makes a revision of this conclusion necessary.

\section{ACV: a new nucleoside HIV-1 reverse transcriptase inhibitor}

Recently, we reported on a surprising insight into the anti-HIV activity of ACV in patients co-infected with HIV and HSV-2. We found that ACV-TP, but not ACV itself, inhibits HIV-1 RT in a cell-free system [32]. This finding was recently confirmed by a group from Johns Hopkins University (MD, USA) [33]. As soon as ACV is transformed into an ACV-TP in HSV-2-infected cells, it suppresses both HSV-2 and HIV-1 (Figure 1). This provides a new explanation for the decrease of HIV load in HSV-2co-infected patients treated with ACV.

In human lymphoid tissues ex vivo that are treated with ACV and are not infected with HSV-2, HIV replication was found to be suppressed as well: we found that these tissues were infected with one or several other HHVs that activate ACV into an HIV-1 RT inhibitor (Figure 1). In HHV-free cell lines, where no such activation occurs, HIV-1 replication was not suppressed by ACV. However, when HHVinfected cells were added to these cell lines, ACV was able to suppress HIV-1 replication again. Thus paradoxically, ACV, designed as a specific antiherpetic drug, becomes an HIV inhibitor in the presence of HHVs [32].

These findings suggest that ACV may suppress HIV-1 in a wide range of patients infected by various HHVs. Moreover, for continuous HIV-1 suppression, such a strategy should be based on HHVs other than HSV-2, since this virus is readily suppressed by ACV and therefore will no longer activate $\mathrm{ACV}$ into ACV-TP. Other HHVs that can phosphorylate ACV but are not readily suppressed by this drug since their DNA polymerases are much less sensitive to it than that of HSV-2 [34] may thus provide a continuous supply of ACV-TP. Remarkably, the nonpathogenic and ubiquitous HHV-6 is among such viruses and has been shown ex vivo to activate ACV into an HIV suppressor [32].

\footnotetext{
"These findings suggest that ACV may suppress HIV-1 in a wide range of patients infected by various HHVs."
}

In light of these findings, new targeted clinical trials should evaluate the efficacy of ACV in reducing HIV-1 viral load in individuals coinfected with HHVs other than HSV-2 and who are not qualified for highly active antiretroviral therapy (HAART). In the new clinical trials aimed at preventing HIV-1 acquisition and reducing HIV-1 viral load, the dose of administered ACV should be adjusted to provide the adequate amount of ACV-TP for HIV-1 suppression, rather than for complete HSV-2 suppression. These new clinical trials should answer whether the strategy designed ex vivo would work in vivo and should indicate which HHVs are optimal for supplying ACV-TP and what level of HHV replication is sufficient to provide enough ACV-TP to suppress HIV. Moreover, since HIV eventually develops resistance against nucleoside RT inhibitors, it is important to evaluate whether ACV resistance is acquired in vivo and whether it could affect HIV-1 sensitivity to other anti-HIV drugs and vice versa.

\section{Conclusion}

ACV conversion by HHVs into an anti-HIV-1 drug provides the basis for a new principle of anti-HIV therapy: a 'binary weapon' in which 
an inert compound is converted by an endogenous component into an active therapeutic drug. Generally, since the human body is populated by a large number of microbes, exploiting the metabolic activity of one microbe against another could be a valid strategy in therapy [35].

The use of ACV or its derivatives for HIV suppression is in line with a popular trend to identify new uses for old drugs with a known pharmacokinetic and safety profile [36]. Several such new applications of old drugs have been described in recent years [37]. As far as ACV and its derivatives are concerned, since $\mathrm{HHV}$ s are among the most common infections associated with AIDS, the ability of ACV to dual target both HHVs and
HIV, together with its history of 30 years of safe application, are of great advantage. Therefore, in the future, ACV or its derivatives may become a part of drug cocktails to suppress HIV.

\section{Financial \& competing interests disclosure}

The authors have no relevant affiliations or financial involvement with any organization or entity with a financial interest in or financial conflict with the subject matter or materials discussed in the manuscript. This includes employment, consultancies, honoraria, stock ownership or options, expert testimony, grants or patents received or pending, or royalties.

No writing assistance was utilized in the production of this manuscript.

\section{Bibliography}

1. McGeoch DJ, Cook S, Dolan A, Jamieson FE, Telford EA: Molecular phylogeny and evolutionary timescale for the family of mammalian herpesviruses. J. Mol. Biol. 247, 443-458 (1995).

2. Siegal FP, Lopez C, Hammer GS et al.: Severe acquired immunodeficiency in male homosexuals, manifested by chronic perianal ulcerative herpes simplex lesions. N. Engl. J. Med. 305, 1439-1444 (1981).

3. CDC. 1993 revised classification system for $\mathrm{HIV}$ infection and expanded surveillance case definition for AIDS among adolescents and adults. MMWR Recomm. Rep. 41, 1-19 (1992).

4. Wald A, Link K: Risk of human immunodeficiency virus infection in herpes simplex virus type 2-seropositive persons: a meta-analysis. J. Infect. Dis. 185, 45-52 (2002).

5. Freeman EE, Weiss HA, Glynn JR, Cross PL, Whitworth JA, Hayes RJ: Herpes simplex virus 2 infection increases HIV acquisition in men and women: systematic review and meta-analysis of longitudinal studies. AIDS 20, 73-83 (2006).

6. Mole L, Ripich S, Margolis D, Holodniy M: The impact of active herpes simplex virus infection on human immunodeficiency virus load. J. Infect. Dis. 176, 766-770 (1997).

7. Schacker T, Ryncarz AJ, Goddard J, Diem K, Shaughnessy M, Corey L: Frequent recovery of HIV-1 from genital herpes simplex virus lesions in HIV-1 infected men. JAMA 280, 61-66 (1998).

8. Lusso P, Gallo RC: Human herpesvirus 6 in AIDS. Immunol. Today 16, 67-71 (1995).

9. Grivel JC, Ito Y, Faga G et al:: Suppression of CCR5- but not CXCR4-tropic HIV-1 in lymphoid tissue by human herpesvirus 6 . Nat. Med. 7, 1232-1235 (2001).
10. Lisco A, Grivel JC, Biancotto A et al.: Viral interactions in human lymphoid tissue: human herpesvirus-7 suppresses the replication of CCR5-tropic human immunodeficiency virus type 1 via CD4 modulation. J. Virol. 81, 708-717 (2007).

11. Griffiths PD: CMV as a cofactor enhancing progression of AIDS. J. Clin. Virol. 35, 489-492 (2006).

12. Arora A, Chiao E, Tyring SK: AIDS malignancies. Cancer Treat. Res. 133, 21-67 (2007).

13. Marx JL: The 1988 Nobel Prize for Physiology and Medicine. Science 242(4878), 516-517 (1988).

14. Elion GB: The biochemistry and mechanism of action of acyclovir. J. Antimirob. Chemother. 12, B9-B17 (1983).

15. De Clercq E, Naesens L, De Bolle L, Schols D, Zhang Y, Neyts J: Antiviral agents active against human herpesviruses HHV-6, HHV-7 and HHV-8. Rev. Med. Virol. 11, 381-395 (2001).

16. Reardon JE, Spector T: Herpes simplex virus type 1 DNA polymerase. Mechanism of inhibition by acyclovir triphosphate. J. Biol. Chem. 264, 7405-7411 (1989).

17. Caruso M, Klatzmann D: Selective killing of $\mathrm{CD}^{+}$cells harboring a human immunodeficiency virus-inducible suicide gene prevents viral spread in an infected cell population. Proc. Natl Acad. Sci. USA 89, 182-186 (1992).

18. Delany S, Clayton T, Mlaba N et al.: Impact of HSV-2 suppressive therapy on genital and plasma HIV-1 RNA in HIV-1 and HSV-2seropositive women not taking ART: a randomized, placebo-controlled trial in Johannesburg, South Africa. Presented at: 14 th Conference on Retroviruses and Opportunistic Infections. Los Angeles, CA, USA, 25 February 2007.
19. Nagot N, Ouedraogo A, Foulongne V et al.: Reduction of HIV-1 RNA levels with therapy to suppress herpes simplex virus [see comment]. N. Engl. J. Med. 356, 790-799 (2007).

20. Zuckerman RA, Lucchetti A, Whittington WL et al.: Herpes simplex virus (HSV) suppression with valacyclovir reduces rectal and blood plasma HIV-1 levels in HIV-1/HSV-2-seropositive men: a randomized, double-blind, placebo-controlled crossover trial. J. Infect. Dis. 196, 1500-1508 (2007).

21. Dunne EF, Whitehead S, Sternberg M et al.: Suppressive acyclovir therapy reduces HIV cervicovaginal shedding in HIV- and HSV-2-infected women, Chiang Rai, Thailand. J. Acquir. Immune Defic. Syndr. Hum. Retrovirol. 49, 77-83 (2008).

22. Baeten JM, Strick LB, Lucchetti A et al:: Herpes simplex virus (HSV)-suppressive therapy decreases plasma and genital HIV-1 levels in HSV-2/HIV-1 coinfected women: a randomized, placebo-controlled, cross-over trial. J. Infect. Dis. (2008) (Epub ahead of print).

23. Ioannidis JP, Collier AC, Cooper DA et al.: Clinical efficacy of high-dose acyclovir in patients with human immunodeficiency virus infection: a meta-analysis of randomized individual patient data. J. Infect. Dis. 178, 349-359 (1998).

24. Golden MP, Kim S, Hammer SM et al.: Activation of human immunodeficiency virus by herpes simplex virus. J. Infect. Dis. 166, 494-499 (1992).

25. Margolis DM, Rabson AB, Straus SE, Ostrove JM: Transactivation of the HIV-1 LTR by HSV-1 immediate-early genes. Virology 186, 788-791 (1992).

26. Watson-Jones D, Weiss HA, Rusizoka M et al:: Effect of herpes simplex suppression on incidence of HIV among women in Tanzania [see comment]. N. Engl. J. Med. 358, 1560-1571 (2008). 
27. Celum C, Wald A, Hughes J et al.: Effect of aciclovir on HIV-1 acquisition in herpes simplex virus 2 seropositive women and men who have sex with men: a randomised, double-blind, placebo-controlled trial [see comment]. Lancet 371, 2109-2119 (2008).

28. Lisco A, Vanpouille C: HSV-2 suppression and the incidence of HIV [comment]. N. Engl. J. Med. 359, 535; author reply 535 (2008).

29. Stirratt MJ, Gordon CM: Adherence to biomedical HIV prevention methods: considerations drawn from HIV treatment adherence research. Curr. HIVIAIDS Rep. 5, 186-192 (2008).

30. Hudson CP: Effect of aciclovir on HIV-1 acquisition in HSV-2-positive patients. Lancet 372, 1298 (2008)

31. Powers KA, Poole C, Pettifor AE, Cohen MS: Rethinking the heterosexual infectivity of HIV-1: a systematic review and meta-analysis. Lancet Infect. Dis. 8, 553-563 (2008).

32. Lisco A, Vanpouille C, Tchesnokov EP et al.: Acyclovir is activated into a HIV-1 reverse transcriptase inhibitor in herpesvirus-infected human tissues [see comment]. Cell Host Microbe 4, 260-270 (2008).
33. McMahon MA, Siliciano JD, Lai J et al.: The antiherpetic drug acyclovir inhibits HIV replication and selects the V75i reverse transcriptase multidrug resistance mutation. J. Biol. Chem. 283(46), 31289-31293 (2008).

34. Bapat AR, Bodner AJ, Ting RC, Cheng YC: Identification and some properties of a unique DNA polymerase from cells infected with human B-lymphotropic virus. J. Virol. 63, 1400-1403 (1989).

35. Margolis L: Cytokines: strategic weapons in germ warfare? Nat. Biotechnol. 21, 15-16 (2003).

36. Chong CR, Sullivan DJ Jr: New uses for old drugs [see comment]. Nature 448, 645-646 (2007).

37. Sundar S, Jha TK, Thakur CP et al.: Oral miltefosine for Indian visceral leishmaniasis [see comment]. N. Engl. J. Med. 347, 1739-1746 (2002).

\section{Affiliations}

- Christophe Vanpouille, PhD Program in Physical Biology, Eunice Kennedy Shriver National Institute of Child Health and Human Development,
National Institute of Child Health \& Human Development, 10 Center Drive, Building 10, Room 9D58, Bethesda, MD 20892, USA

Tel.: +1 301594 0826;

Fax: +1 3014800857 ;

vanpouic@mail.nih.gov

Andrea Lisco, MD, PhD

Program in Physical Biology,

Eunice Kennedy Shriver National Institute of Child Health and Human Development, National Institute of Child Health \& Human Development, 10 Center Drive, Building 10, Room 9D58, Bethesda, MD 20892, USA

Tel.: +1 301594 1751;

Fax: +1 301480 0857;

liscoa@mail.nih.gov

- Leonid Margolis, PhD

Program in Physical Biology,

Eunice Kennedy Shriver National Institute of Child Health and Human Development, National Institute of Child Health \& Human Development, 10 Center Drive, Building 10, Room 9D58, Bethesda, MD 20892, USA

Tel.: +1 301594 2476;

Fax: +1 301480 0857;

margolil@mail.nih.gov 